\title{
SNCA mutation p.Ala53Glu is derived from a common founder in the Finnish population
}

Pasanen, Petra

2017

Pasanen , P , Palin , E , Pohjolan-Pirhonen , R , Pöyhönen , M , Rinne , J O , Päivärinta , M , Martikainen, M H , Kaasinen , V , Hietala , M , Gardberg , M , Saukkonen , A M , Eerola-Rautio , J , Kaakkola , S , Lyytinen , J , Tienari , P , Paetau , A, Suomalainen , A \& Myllykangas , L 2017 , ' SNCA mutation p.Ala53Glu is derived from a common founder in the Finnish population ' , Neurobiology of Aging , vol. 50 , 168.e5 . https://doi.org/10.1016/j.neurobiolaging.2016.10.014

http://hdl.handle.net/10138/236417

https://doi.org/10.1016/j.neurobiolaging.2016.10.014

publishedVersion

Downloaded from Helda, University of Helsinki institutional repository.

This is an electronic reprint of the original article.

This reprint may differ from the original in pagination and typographic detail.

Please cite the original version. 
Brief communication

\title{
SNCA mutation p.Ala53Glu is derived from a common founder in the Finnish population
}

\author{
Petra Pasanen $^{\text {a,b }}$, Eino Palin ${ }^{c}$, Risto Pohjolan-Pirhonen ${ }^{c}$, Minna Pöyhönen ${ }^{\text {d,e }}$, \\ Seppo Kaakkola ${ }^{\mathrm{m}}$, Jukka Lyytinen ${ }^{\mathrm{m}}$, Pentti J. Tienari ${ }^{\mathrm{c}, \mathrm{m}}$, Anders Paetau ${ }^{\mathrm{n}}$, \\ Anu Suomalainen ${ }^{\mathrm{C}}$, Liisa Myllykangas ${ }^{\mathrm{n}, *}$ \\ ${ }^{a}$ Department of Medical Biochemistry and Genetics, University of Turku, Turku, Finland \\ ${ }^{\mathrm{b}}$ Department of Medical Genetics, Tyks Microbiology and Genetics, Turku University Hospital, Turku, Finland \\ ${ }^{\mathrm{c}}$ Molecular Neurology, Research Programs Unit, University of Helsinki, Helsinki, Finland \\ ${ }^{\mathrm{d}}$ Department of Clinical Genetics, Helsinki University Central Hospital, Helsinki, Finland \\ e Department of Medical Genetics, University of Helsinki, Helsinki, Finland \\ ${ }^{\mathrm{f}}$ Turku PET Centre, Turku University Hospital and University of Turku, Turku, Finland \\ ${ }^{g}$ Division of Clinical Neurosciences, Turku University Hospital and University of Turku, Turku, Finland \\ ${ }^{\mathrm{h}}$ Visby Lasarett, Visby, Sweden \\ i Department of Neurology, University of Turku, Turku, Finland \\ ${ }^{\mathrm{j}}$ Department of Clinical Genetics, Turku University Hospital, Turku, Finland \\ k Department of Pathology, Turku University Hospital and University of Turku, Turku, Finland \\ ${ }^{1}$ Department of Neurology, North Karelia Central Hospital, Joensuu, Finland \\ ${ }^{\mathrm{m}}$ Department of Neurology, University of Helsinki and Helsinki University Hospital, Helsinki, Finland \\ ${ }^{\mathrm{n}}$ Department of Pathology, University of Helsinki and HUSLAB, Helsinki, Finland
} Juha O. Rinne $^{\mathrm{f}, \mathrm{g}}$, Markku Päivärinta ${ }^{\mathrm{h}}$, Mika H. Martikainen ${ }^{\mathrm{g}}$, Valtteri Kaasinen ${ }^{\mathrm{f}, \mathrm{g}, \mathrm{i}}$, Marja Hietala $^{j}$, Maria Gardberg ${ }^{k}$, Anna Maija Saukkonen ${ }^{1}$, Johanna Eerola-Rautio ${ }^{c, m}$,

\section{A R T I C L E I N F O}

\section{Article history:}

Received 12 September 2016

Accepted 9 October 2016

\section{Keywords:}

SNCA

A53E

Haplotype

Founder effect

\begin{abstract}
A B S T R A C T
Mutations in SNCA are rare causes of familial Parkinson's disease(PD). We have previously described a novel p.Ala53Glu mutation in 2 Finnish families. To assess this mutation's frequency among Finnish PD patients, we screened 110 PD patients (mean age-of-onset 60 years) from Western Finland by Sanger sequencing of the third coding exon of SNCA. In addition, a sample of 47 PD subjects (mean age-of-onset 53 years) originating from Southern and Eastern Finland were studied using next-generation sequencing covering SNCA. Only one new individual with the p.Ala53Glu mutation was identified, confirming that this mutation is a rare cause of PD in the Finnish population. To search for a possible common origin of the p.Ala53Glu mutation, haplotype analysis was conducted in 2 families and in a patient from a third family (6 affected subjects) using both STR markers and a genome-wide SNP array. The results show that patients with the p.Ala53Glu mutation share a haplotype spanning a minimum of $5.7 \mathrm{Mb}$ suggesting a common founder.
\end{abstract}

(c) 2016 Elsevier Inc. All rights reserved.

\section{Introduction}

The SNCA gene on $4 \mathrm{q} 22.1$ codes for a $17-\mathrm{kDa}$ protein predominantly expressed in brain, especially in presynaptic terminals. The exact functions of SNCA are still somewhat unclear, but it is likely involved in modulation of synaptic activity by participating in vesicle release (Bendor et al., 2013). Aggregated SNCA proteins form inclusions that are the classical findings in neurodegenerative synucleinopathies: Parkinson's disease (PD), dementia with Lewy

\footnotetext{
* Corresponding author at: Department of Pathology, University of Helsinki, POB 21, Helsinki FIN-00014, Finland. Tel.: +358-50-4482805; fax: +358-2941-26700. E-mail address: liisa.myllykangas@helsinki.fi (L. Myllykangas).
}

bodies and multiple system atrophy (MSA). Multiplications (Chartier-Harlin et al., 2004; Singleton et al., 2003) and point mutations, p.Ala30Pro (Krüger et al., 1998), p.Glu46Lys (Zarranz et al., 2004), p.His50Gln (Appel-Cresswell et al., 2013), p.Gly51Asp (Kiely et al., 2013), p.Ala53Thr (Polymeropoulos et al., 1997), p.Ala53Glu (Pasanen et al., 2014), of SNCA have been implicated in rare, autosomal dominant $P D$ spectrum disorders.

We previously reported a novel SNCA p.Ala53Glu mutation in a Finnish family with atypical Parkinson's disease in 3 patients. Neuropathological examination of the index patient showed highly abundant alpha-synuclein pathology throughout the brain and spinal cord with features of both MSA and PD. The SNCA p.Ala53Glu mutation was seen in all the 3 affected family members 
(Pasanen et al., 2014). Functional studies have shown that the p.Ala53Glu mutation reduces alpha-synuclein fibril formation and enhances toxicity in cells under stress due to mitochondrial impairment (Ghosh et al., 2014; Rutherford and Giasson, 2015). The p.Ala53Glu mutant protein also has a lower membrane binding affinity than the wild type protein (Ghosh et al., 2014).

Since the first report, the p.Ala53Glu mutation was reported in another Finnish family with autosomal dominant PD by Martikainen et al. (2015). The mutation was detected in 2 affected patients of the family.

These findings prompted us to investigate how common this mutation is among Finnish PD patients. We screened a larger cohort of PD patients for the p.Ala53Glu mutation. In addition, we performed a haplotype analysis that demonstrated a shared haplotype in all individuals with the mutation. Our findings show that the SNCA p.Ala53Glu mutation is rare and originates from a common founder in the Finnish population.

\section{Material and methods}

\subsection{PD patients}

\subsubsection{Families $F 1$ and $F 2$}

Families F1 and F2 have been described before (Martikainen et al., 2015; Pasanen et al., 2014). Seven DNA samples were available from these families.

\subsubsection{PD patient cohorts}

Autopsy-derived deep-frozen brain samples were available from 45 PD patients, who were neuropathologically verified as PD (24 males, 21 females; mean age at onset: 64.2 years [range $47-80$, SD \pm 7.7 years]; mean disease duration: 11.5 years [range $3-20, \mathrm{SD}$ \pm 4.4 years]; mean age at death: 75.7 years [range 50-88, $\mathrm{SD} \pm 7.3$ years]). Three patients also had neuritic plaques suggestive of Alzheimer's disease. Blood-derived DNA samples were available from additional 65 patients with clinically diagnosed PD (40 males, 25 females, mean age at onset: 57.8 years [range 37-79, SD \pm 9 years]; mean disease duration: 10.3 years [range $2-21$, SD \pm 5.6 years]). These 110 patients were of Western Finnish origin. Informed consent was obtained from the patients or their appropriate next of kin. Ethical approval for the study was given by the ethics review board of Turku University Hospital.

Blood-derived DNA samples were available from 47 early-onset PD patients. These patients originated from Southern and Eastern Finland (20 males, 27 females; mean age at onset 53 years). Informed consent was obtained from the patients or their appropriate next of kin. Ethical approval for the study was given by the ethics review board of Helsinki University Central Hospital and institutional review board of North Karelia Central Hospital.

\subsection{Genetic analyses}

In the postmortem cohort, DNAs were extracted from deepfrozen tissue using NucleoSpin Tissue kit (Macherey-Nagel, Düren, Germany). DNAs from blood samples were extracted with standard protocols. Exon 4 (the third coding exon) of SNCA was amplified by PCR using primers For: 5'-gctaatcagcaatttaaggctag-3' and Rev: $5^{\prime}$-gatatgttcttagaatgctcag-3'. Purified PCR products were sequenced in both directions using the BigDye Terminator v3.1 Cycle Sequencing Kit (Applied Biosystems, CA, USA).

The cohort of 47 PD patients was screened for mutations in PD loci by using HaloPlex targeted sequencing of 82 selected PD-associated loci (Agilent Technologies, Santa Clara, CA, USA). The sequencing was done with MiSeq sequencer (Illumina, San Diego, CA, USA). Variant calling was done with Genome Analysis Toolkit
(McKenna et al., 2010) and the annotation with ANNOVAR (Wang et al., 2010).

Eight STR markers flanking a $\sim 10-\mathrm{Mb}$ area around SNCA were amplified by PCR using a 6-FAM-labeled reverse primer. PCR products were separated on an $A B I 3730 x$ capillary sequencer (Applied Biosystems, Foster City, CA, USA) and analyzed with the GeneMarker software (Softgenetics LLC, State College, PA, USA). In addition, all available samples from the 3 families were analyzed on a genome-wide SNP array (Human CoreExome BeadChip, Illumina, San Diego, CA, USA). Genotyping was performed by the Institute for Molecular Medicine Finland FIMM Technology Centre, University of Helsinki. Haplotype phases in the SNCA area and flanking regions were determined as stretches of SNP genotypes concordant for one or both alleles in patients from all the 3 families. Informative markers in parent-offspring duos in families F1 and F2 were used for phasing and the genotypes from patient F3 III:3 were compared with the phased genotypes.

\section{Results}

Sanger sequencing of SNCA exon 4 did not reveal any individuals with the p.Ala53Glu mutation in the cohort of 110 PD patients from Western Finland.

One new patient with the p.Ala53Glu mutation was identified in the cohort of $47 \mathrm{PD}$ patients through targeted sequencing of 82 PD-associated genes. This patient presented with typical PD signs at the age of 41 . At the age 43 , the disease had progressed slowly and she did not require levodopa medication. She had dysphagia and dysarthria. [123I]beta-CIT SPECT imaging showed lowered dopamine transporter binding at the right putamen and caudate nucleus. Family history was compatible with autosomal dominant inheritance with at least 2 other affected family members (the index patient's mother and sister). Maternal grandmother may also have been affected by PD.

Haplotype analysis suggested that the patients with the p.Ala53Glu mutation share a common haplotype on chromosome 4. Phased STR marker haplotype in families F1 and F2 showed that the shared genomic segment spans the area between STR markers D4S2371 and D4S2380. The unphased STR markers of the singleton patient from family F3 had alleles consistent with this haplotype. Based on the physical locations of the markers, the shared region is at least $5.7 \mathrm{Mb}$ in size, starting at marker D4S2371 (genomic location on chr4: 90,132,775) and extending to D4S2380 (genomic location on chr4: 95,883,055; Fig. 1). Analysis of the SNP data suggested breakages of the mutation-bearing haplotype at SNP rs2116325 (chr4: 90,115,197) and rs6842919 (chr4: $106,958,170$ ) located $16.8 \mathrm{Mb}$ from each other. The putative shared haplotype inferred from informative markers is shown in the Supplementary Table 1.

\section{Discussion}

Our results show that the SNCA p.Ala53Glu mutation is a rare cause of PD in the Finnish population. The mutation has been previously reported in 2 Finnish families originating from Western Finland, but no new patients with the mutation were identified in screening of 110 PD cases from Western Finland. One new case was identified in a family from Eastern Finland. In agreement with our results, no SNCA mutations were found in a cohort of 22 unrelated Eastern and Northern Finnish familial PD patients (Autere et al., 2002). The p.Ala53Glu mutation has not been reported in the 1000 Genomes, ExAC, ESP, or SISu databases (accessed June 2016).

The PD patients of the cohort from Western Finland were mostly sporadic, with mean age at onset of 60.4 years, whereas the patients from the cohort of 47 subjects were familial, with mean age at onset 
F1

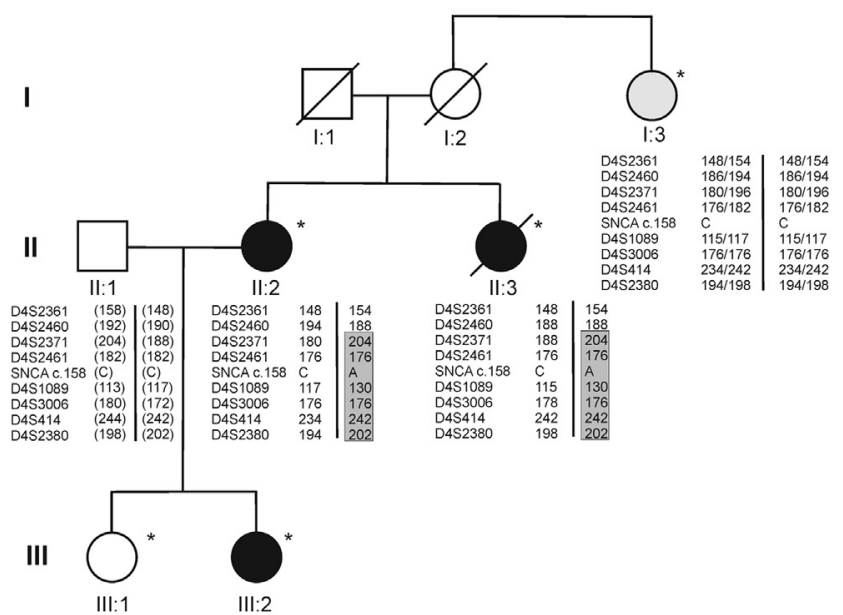

F2

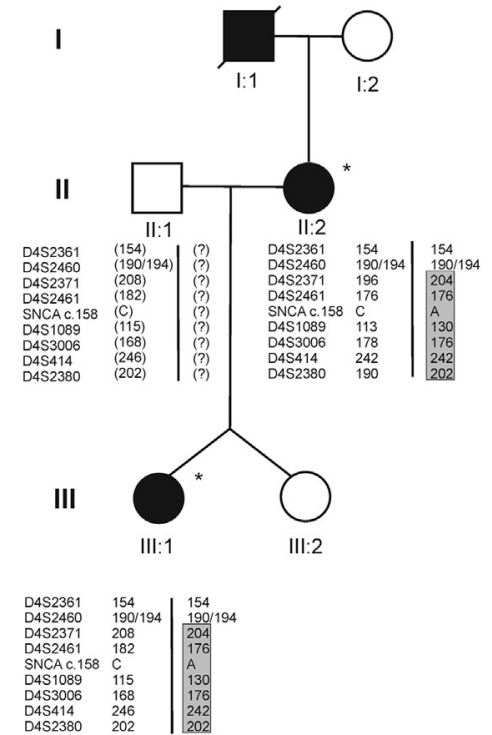

F3

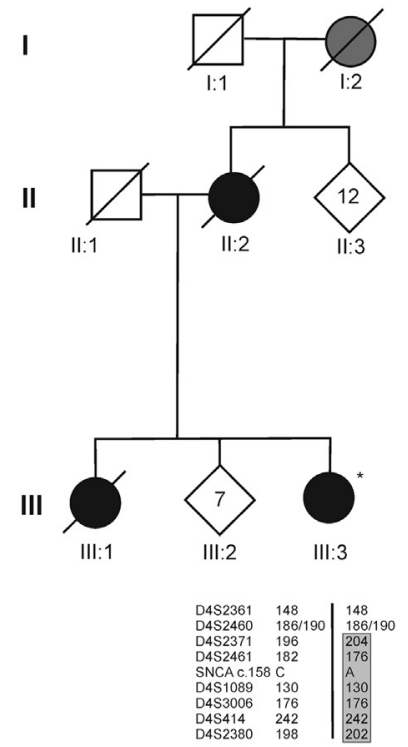

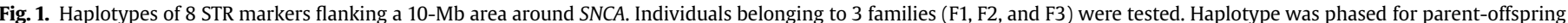

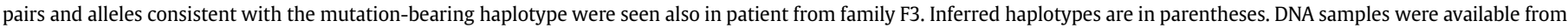

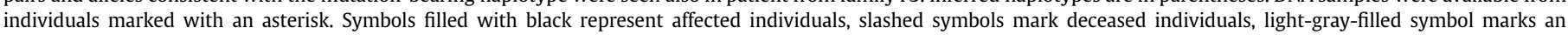

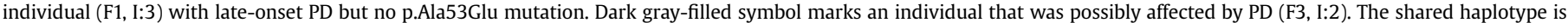
marked with a gray rectangle.

of 53 years. Thus, the lack of known family history in the PD cohort from Western Finland may have contributed to results. However, many autosomal dominant mutations have been identified in apparently sporadic cases of neurological diseases, such as FTD/ALS due to hexanucleotide expansion in C9orf72 (Renton et al., 2011). Furthermore, the age-of-onset may vary even within families as demonstrated by family F1: the index patient developed symptoms at 36 years; her sister only noted first symptoms at 62 years, the index patient's niece was severely affected at 32 years. The same trend was noted in family F2 with the index patient presenting at 42 years and her daughter at 25 years of age.

The clinical manifestation of the mutation is also variable. In the family F1, the index patient's neuropathological examination revealed features of both PD and MSA, whereas the affected individuals of family F2 presented with hypokinetic-rigid PD and developed severe levodopa-induced dyskinesia. The patient from family F3 has severe dysarthria and dysphagia, which may suggest cereberral involvement and thus features of MSA-C-type disease. Hence, the clinical phenotype linked to the mutation seems to vary from dyskinesia-prone PD to MSA-type disease with cognitive and psychiatric symptoms.

The Finnish population is a classic example of small founder population and genetic bottlenecks leading to regional clusters of rare diseases, most of them autosomal recessive. As a consequence, it is expected that rare mutations originate from a single mutation event in the past. The families reported here had no known connection based on patient interviews but genetic data suggest that they share a common ancestor. No clinical information is available for the older family members of the families F1 and F2, but based on the haplotype analysis, the mutation must have been present in the seemingly unaffected generations, for example, generation I in family F1. This raises the possibility of incomplete penetrance, which has also been suggested for the p.Ala53Thr mutation (Papadimitriou et al., 1999; 2016) and is commonly observed in many autosomally dominantly inherited disorders
(Cooper et al., 2013). Thus, it is likely that there are more individuals with this mutation in the Finnish population, some of which may appear asymptomatic or sporadic.

The p.Ala53Glu mutation resides in the same amino acid position as the first identified SNCA mutation, p.Ala53Thr. The SNCA p.Ala53Thr mutation was first reported in an Italian family, the Contursi kindred, and in 3 seemingly unrelated Greek families (Polymeropoulos et al., 1997). Haplotype analysis suggested that the Italian and Greek p.Ala53Thr families shared a common ancestor (Athanassiadou et al., 1999). Consequently, the p.Ala53Thr seems to be most common in families of Greek or Italian origin. A few patients from other populations have been described: an apparently sporadic late-onset case from Poland (Michell et al., 2005), a Korean family (Ki et al., 2007), and a Swedish family with a de novo p.Ala53Thr mutation (Puschmann et al., 2009). These results show that the position coding for amino acid 53 has undergone several mutation events in different populations.

\section{Conclusions}

In conclusion, we have shown that all known Finnish PD patients with the p.Ala53Glu mutation share the same haplotype surrounding SNCA on chromosome $4 \mathrm{q} 22$, consistent with a common ancestor. The clinical manifestations of the mutation are variable within and between families, suggesting that additional genetic and environmental factors modulate the phenotypic presentation. There might be more patients with the p.Ala53Glu mutation in the Finnish population and screening for $S N C A$ is recommended particularly in subjects with severe, early-onset PD.

\section{Disclosure statement}

The authors declare no actual or potential conflicts of interest. 


\section{Acknowledgements}

The authors thank the patients and their family members. This study was financially supported by Päivikki and Sakari Sohlberg Foundation (Petra Pasanen, Liisa Myllykangas), Academy of Finland (Liisa Myllykangas), Helsinki University Hospital competite fund (ERVA; Liisa Myllykangas), the Sigrid Jusélius Foundation (Mika H. Martikainen), Pirkko and Veikko Mäkelä Foundation (Petra Pasanen), Finnish Cultural Foundation, Kymenlaakso Regional Fund (Petra Pasanen).

\section{Appendix A. Supplementary data}

Supplementary data associated with this article can be found, in the online version, at http://dx.doi.org/10.1016/j.neurobiolaging. 2016.10.014.

\section{References}

Appel-Cresswell, S., Vilarino-Guell, C., Encarnacion, M., Sherman, H., Yu, I., Shah, B., Weir, D., Thompson, C., Szu-Tu, C., Trinh, J., Aasly, J.O., Rajput, A., Rajput, A.H., Jon Stoessl, A., Farrer, M.J., 2013. Alpha-synuclein p.H50Q a novel pathogenic mutation for Parkinson's disease. Mov. Disord. 28, 811-813.

Athanassiadou, A. Voutsinas, G., Psiouri, L., Leroy, E., Polymeropoulos, M. H. Ilias, A. Maniatis, G.M., Papapetropoulos, T., 1999. Genetic analysis of families with Parkinson disease that carry the Ala53Thr mutation in the gene encoding alphasynuclein. Am. J. Hum. Genet. 65, 555-558.

Autere, J.M., Hiltunen, M.J., Mannermaa, A.J., Jäkälä, P.A., Hartikainen, P.H., Majamaa, K., Alafuzoff, I., Soininen, H.S., 2002. Molecular genetic analysis of the alpha-synuclein and the parkin gene in Parkinson's disease in Finland. Eur. J. Neurol. 9, 479-483.

Bendor, J.T., Logan, T.P., Edwards, R.H., 2013. The function of $\alpha$-synuclein. Neuron 79, 1044-1066.

Chartier-Harlin, M.C., Kachergus, J., Roumier, C., Mouroux, V., Douay, X., Lincoln, S., Levecque, C., Larvor, L., Andrieux, J., Hulihan, M., Waucquier, N., Defebvre, L., Amouyel, P., Farrer, M., Destée, A., 2004. Alpha-synuclein locus duplication as a cause of familial Parkinson's disease. Lancet 364, 1167-1169.

Cooper, D.N., Krawczak, M., Polychronakos, C., Tyler-Smith, C., Kehrer-Sawatzki, H. 2013. Where genotype is not predictive of phenotype: towards an understanding of the molecular basis of reduced penetrance in human inherited disease. Hum. Genet. 132, 1077-1130.

Ghosh, D., Sahay, S., Ranjan, P., Salot, S., Mohite, G.M., Singh, P.K., Dwivedi, S., Carvalho, E., Banerjee, R., Kumar, A., Maji, S.K., 2014. The newly discovered Parkinson's disease associated Finnish mutation (A53E) attenuates $\alpha$-synuclein aggregation and membrane binding. Biochemistry 53, 6419-6421.

Ki, C.S., Stavrou, E.F., Davanos, N., Lee, W.Y., Chung, E.J., Kim, J.Y., Athanassiadou, A., 2007. The Ala53Thr mutation in the alpha-synuclein gene in a Korean family with Parkinson disease. Clin. Genet. 71, 471-473.

Kiely, A.P., Asi, Y.T., Kara, E., Limousin, P., Ling, H., Lewis, P., Proukakis, C., Quinn, N., Lees, A.J., Hardy, J., Revesz, T., Houlden, H., Holton, J.L., 2013. $\propto$-Synucleinopathy associated with G51D SNCA mutation: a link between Parkinson's disease and multiple system atrophy? Acta Neuropathol. 125, 753-769.

Krüger, R., Kuhn, W., Müller, T., Woitalla, D., Graeber, M., Kösel, S., Przuntek, H., Epplen, J.T., Schöls, L., Riess, O., 1998. Ala30Pro mutation in the gene encoding alpha-synuclein in Parkinson's disease. Nat. Genet. 18, 106-108.
Martikainen, M.H., Päivärinta, M., Hietala, M., Kaasinen, V., 2015. Clinical and imaging findings in Parkinson disease associated with the A53E SNCA mutation. Neurol. Genet. 1, e27.

McKenna, A., Hanna, M., Banks, E., Sivachenko, A., Cibulskis, K., Kernytsky, A. Garimella, K., Altshuler, D., Gabriel, S., Daly, M., DePristo, M.A., 2010. The Genome Analysis Toolkit: a MapReduce framework for analyzing nextgeneration DNA sequencing data. Genome Res. 20, 1297-1303.

Michell, A.W., Barker, R.A., Raha, S.K., Raha-Chowdhury, R., 2005. A case of late onset sporadic Parkinson's disease with an A53T mutation in alpha-synuclein. J. Neurol. Neurosurg. Psychiatry 76, 596-597.

Papadimitriou, A., Veletza, V., Hadjigeorgiou, G.M., Patrikiou, A., Hirano, M., Anastasopoulos, I., 1999. Mutated alpha-synuclein gene in two Greek kindreds with familial PD: incomplete penetrance? Neurology 52, 651-654.

Papadimitriou, D., Antonelou, R., Miligkos, M., Maniati, M., Papagiannakis, N. Bostantjopoulou, S., Leonardos, A., Koros, C., Simitsi, A., Papageorgiou, S.G. Kapaki, E., Alcalay, R.N., Papadimitriou, A., Athanassiadou, A., Stamelou, M., Stefanis, L., 2016. Motor and nonmotor features of carriers of the p.A53T alphasynuclein mutation: a longitudinal study. Mov. Disord. 31, 1226-1230.

Pasanen, P., Myllykangas, L., Siitonen, M., Raunio, A., Kaakkola, S., Lyytinen, J., Tienari, P.J., Pöyhönen, M., Paetau, A., 2014. A novel $\alpha$-synuclein mutation A53E associated with atypical multiple system atrophy and Parkinson's disease-type pathology. Neurobiol. Aging 35, 2180.e1-2180.e5.

Polymeropoulos, M.H., Lavedan, C., Leroy, E., Ide, S.E., Dehejia, A., Dutra, A., Pike, B. Root, H., Rubenstein, J., Boyer, R., Stenroos, E.S., Chandrasekharappa, S. Athanassiadou, A., Papapetropoulos, T., Johnson, W.G., Lazzarini, A.M. Duvoisin, R.C., Di Iorio, G., Golbe, L.I., Nussbaum, R.L., 1997. Mutation in the alpha-synuclein gene identified in families with Parkinson's disease. Science 276, 2045-2047.

Puschmann, A., Ross, O.A., Vilariño-Güell, C., Lincoln, S.J., Kachergus, J.M., Cobb, S.A. Lindquist, S.G., Nielsen, J.E., Wszolek, Z.K., Farrer, M., Widner, H., van Westen, D. Hägerström, D., Markopoulou, K., Chase, B.A., Nilsson, K., Reimer, J., Nilsson, C. 2009. A Swedish family with de novo alpha-synuclein A53T mutation: evidence for early cortical dysfunction. Parkinsonism Relat. Disord. 15, 627-632.

Renton, A.E., Majounie, E., Waite, A., Simón-Sánchez, J., Rollinson, S., Gibbs, J.R. Schymick, J.C., Laaksovirta, H., van Swieten, J.C., Myllykangas, L., Kalimo, H., Paetau, A., Abramzon, Y., Remes, A.M., Kaganovich, A., Scholz, S.W. Duckworth, J., Ding, J., Harmer, D.W., Hernandez, D.G., Johnson, J.O., Mok, K. Ryten, M. Trabzuni, D. Guerreiro, R.J., Orrell, R.W., Neal, J., Murray, A Pearson, J., Jansen, I.E., Sondervan, D., Seelaar, H., Blake, D., Young, K. Halliwell, N., Callister, J.B., Toulson, G., Richardson, A., Gerhard, A., Snowden, J. Mann, D. Neary, D. Nalls, M.A., Peuralinna, T., Jansson, L., Isoviita, V.M., Kaivorinne, A.L., Hölttä-Vuori, M., Ikonen, E., Sulkava, R., Benatar, M., Wuu, J. Chiò, A., Restagno, G., Borghero, G., Sabatelli, M., Heckerman, D., Rogaeva, E., Zinman, L., Rothstein, J.D., Sendtner, M., Drepper, C., Eichler, E.E., Alkan, C., Abdullaev, Z., Pack, S.D., Dutra, A., Pak, E., Hardy, J., Singleton, A., Williams, N.M. Heutink, P., Pickering-Brown, S., Morris, H.R., Tienari, P.J., Traynor, B.J. ITALSGEN Consortium, 2011. A hexanucleotide repeat expansion in C9ORF72 is the cause of chromosome 9p21-linked ALS-FTD. Neuron 72, 257-268.

Rutherford, N.J., Giasson, B.I., 2015. The A53E $\alpha$-synuclein pathological mutation demonstrates reduced aggregation propensity in vitro and in cell culture. Neurosci. Lett. 597, 43-48.

Singleton, A.B., Farrer, M., Johnson, J. Singleton, A., Hague, S., Kachergus, J., Hulihan, M., Peuralinna, T., Dutra, A., Nussbaum, R., Lincoln, S., Crawley, A., Hanson, M., Maraganore, D., Adler, C., Cookson, M.R., Muenter, M., Baptista, M. Miller, D., Blancato, J., Hardy, J., Gwinn-Hardy, K., 2003. alpha-Synuclein locus triplication causes Parkinson's disease. Science 302, 841

Wang, K., Li, M., Hakonarson, H., 2010. ANNOVAR: functional annotation of genetic variants from high-throughput sequencing data. Nucleic Acids Res. 38, e164.

Zarranz, J.J., Alegre, J., Gómez-Esteban, J.C., Lezcano, E., Ros, R., Ampuero, I., Vidal, L Hoenicka, J., Rodriguez, O., Atarés, B., Llorens, V., Gomez Tortosa, E., del Ser, T. Muñoz, D.G., de Yebenes, J.G., 2004. The new mutation, E46K, of alpha-synuclein causes Parkinson and Lewy body dementia. Ann. Neurol. 55, 164-173. 